\title{
Lectin Variation in Members of Rhizoctonia Species
}

\author{
Mwafaida J. Mghalu ${ }^{1}$, Yuka Kobayashi², HirokaZu Kawagishi ${ }^{2}$ and Mitsuro HyakumaChi ${ }^{3 *}$ \\ ${ }^{1}$ United Graduate School of Agricultural Sciences, Gifu University, Yanagido 1-1, Gifu, 501-1193, Japan \\ ${ }^{2}$ Faculty of Agriculture, Department of Applied Biological Chemistry, Shizuoka University, 836 Ohya, Shizuoka, \\ 422-8529, Japan \\ ${ }^{3}$ Faculty of Applied Biological Sciences, Laboratory of Plant Pathology, Gifu University, Yanagido 1-1, Gifu, \\ 501-1193, Japan
}

(Received November 11, 2003-Accepted March 27, 2004)

Isolates from two multinucleate Rhizoctonia species, namely Rhizoctonia solani and Rhizoctonia circinata, and binucleate Rhizoctonia spp., were evaluated for the presence of lectins, using human erythrocytes. Isolates from $R$. solani had similar lectins across the anastomosis groups. Agglutination profiles, however, revealed individual preferences for human blood types but with a general preference for type A over B and O. R. solani lectins had a general affinity for $\mathrm{N}$-acetyl-D-galactosamine and mucin. Also, some isolates from the binucleate Rhizoctonia AG-DII, had lectins that showed strong affinity for glycoproteins, fetuin and mucin. There was no lectin activity in members of $R$. circinata. The lectins in members of the genus Rhizoctonia varied in content and character across the species sampled but had similar affinity for mucin. Furthermore, $62 \%$ of the self-anastomosing and $35 \%$ of the non-self anastomosing isolates tested showed lectin activity. The presence of lectins in both self-anastomosing and non-self anastomosing isolates suggests that lectins may not be directly involved in the recognition process in hyphal anastomosis.

Key words: Rhizoctonia spp., lectin variation, anastomosis

Rhizoctonia fungi are known to be pathogenic to a wide range of host plants. The genus Rhizoctonia is divided into uninucleate, binucleate and multinucleate types with $R$. solani and $R$. circinata being multinucleate types. Isolates of Rhizoctonia species have been placed further into anastomosis groups (AG) based on their hyphal anastomosis behavior $^{21)}$. Members of $R$. solani have been assigned to 13 AGs running from AG 1 through 13 15,16,17,19,21). On the other hand, isolates of $R$. circinata have been assigned to four varieties based on cultural morphology ${ }^{22)}$. Previously, isolates of binucleate Rhizoctonia (BNR) except AG-Q had been assigned to 20 AGs from AG-A through AG-U ${ }^{18,20,21)}$. However, based on fatty acid composition, and RFLP and RAPD analyses, AG-Q had been reassigned to a subgroup of $\mathrm{AG}-\mathrm{D}^{20,23)}$. Also, the presence of clamp connections in isolates of AG-J and AG-M (Ogoshi; personal communica-

\footnotetext{
* Corresponding author; Email: hyakumac@cc.gifu-u.ac.jp, Tel \& fax: +81-58-293-2847
}

tion) excludes these two groups from the genus Rhizoctonia. This further reduces the AG number to 18. So far, isolates of uninucleate Rhizoctonia have been reported in conifer seedlings in Finland and Norway ${ }^{7}$.

Recently, the presence of lectins on the hyphal surfaces and tissues of Rhizoctonia fungi has been reported ${ }^{4,11,12,13,24)}$. These findings, however, were based on limited groups of Rhizoctonia spp. Lectins are sugar-binding proteins that agglutinate cells and precipitate glyco-conjugates ${ }^{6}$. Biologically they are more active as aggregates, generally dimers or tetramers, than monomers and are involved in interactions between the cell surface and extracellular environment ${ }^{3)}$. Lectins are highly specific and can discriminate between different types of cells that have only minor variations. Their ability to discriminate between human red blood cells (A, B and $\mathrm{O}$ ) that have different terminal non-reducing sugars in their major glycoprotein has been used in their partial characterization $^{25)}$. Studies have shown that the ability of lectins to bind carbohydrates is directly involved in fungal- 
Table 1. Isolates used in this study

\begin{tabular}{|c|c|c|}
\hline Species/Sub-groups & Isolate & Host $^{\text {source }}$ \\
\hline \multicolumn{3}{|l|}{ R. solani } \\
\hline \multirow[t]{5}{*}{ AG 1-IA } & RRC-97-1 & Rice \\
\hline & G7 & Rice \\
\hline & GN-02-1 & Rice \\
\hline & C54 & Rice \\
\hline & Mong 390 & Rice \\
\hline \multirow[t]{3}{*}{ AG 1-IB } & TR 22 & Kentucky grass \\
\hline & $\mathrm{R} 147$ & White clover \\
\hline & LF-08-1 & European pear \\
\hline \multirow[t]{5}{*}{ AG 1-IC } & $\mathrm{F} 1$ & Sugar beet \\
\hline & IR4 & Pine \\
\hline & BW3 & Buckwheat \\
\hline & 189 & Cauliflower \\
\hline & $\mathrm{P} 1$ & Sugar beet \\
\hline \multirow[t]{3}{*}{ AG 1-ID } & $\mathrm{RCP}-1$ & Coffee $^{\mathrm{a}}$ \\
\hline & $\mathrm{RCP}-3$ & Coffee $^{a}$ \\
\hline & $\mathrm{RCP}-7$ & Coffee $^{a}$ \\
\hline \multirow[t]{3}{*}{ AG 2-1 } & B-1 & $\mathrm{Nd}^{\mathrm{b}}$ \\
\hline & SH-10 & Soil \\
\hline & SH-20 & Soil \\
\hline \multirow[t]{5}{*}{ AG 2-2IIIB } & PGR-01-1 & Bent grass \\
\hline & AS-5-S-IS & $\mathrm{Nd}^{\mathrm{b}}$ \\
\hline & Gu-1 & Guzmania \\
\hline & AK 96-7 & $N d^{b}$ \\
\hline & K2-8 & Bent grass \\
\hline \multirow[t]{7}{*}{ AG 2-2IV } & SA-1 & Sugar beet \\
\hline & P 1211 & SA-1 progeny \\
\hline & H16 & Sugar beet \\
\hline & R94 & Sugar beet \\
\hline & Rh 509 & Sugar beet \\
\hline & 92155 & Sugar beet \\
\hline & S-2 & Sugar beet \\
\hline \multirow[t]{7}{*}{ AG 2-t } & 2TR102 & Tulip $^{\mathrm{c}}$ \\
\hline & 2TR103 & Tulip $^{c}$ \\
\hline & 2TR 116 & Tulip $^{c}$ \\
\hline & 2TR 117 & $\operatorname{Ixia}^{\mathrm{c}}$ \\
\hline & 2TR122 & Tulip $^{c}$ \\
\hline & 2 TR134 & Tulip $^{c}$ \\
\hline & 2TR 137 & Tulip $^{\mathrm{c}}$ \\
\hline \multirow[t]{6}{*}{ AG 2-2LP } & M16-h & Zoysia grass \\
\hline & AJ1-10-1 & Zoysia grass \\
\hline & C4-h & Zoysia grass \\
\hline & M10-d2 & Zoysia grass \\
\hline & M1-m & Zoysia grass \\
\hline & M 23-h & Zoysia grass \\
\hline \multirow[t]{3}{*}{ AG 2-3 } & $\mathrm{R}-4$ & Soybean \\
\hline & H5-316 & Soybean \\
\hline & H5-354 & Soybean \\
\hline
\end{tabular}

\begin{tabular}{|c|c|}
\hline R1 & Soybean \\
\hline R8 & Soybean \\
\hline H4-30 & Soybean \\
\hline SF-BV-1 & Soil \\
\hline SHC-81 & Soil \\
\hline P-5 & Potato \\
\hline 1Sal3 & Potato \\
\hline 1Sal 4 & Potato \\
\hline SR-5 & $\mathrm{Nd}^{\mathrm{b}}$ \\
\hline SP-5 & Potato $^{\mathrm{d}}$ \\
\hline SP-15 & Potato $^{d}$ \\
\hline R468 & Potato \\
\hline $521-21$ & Soil \\
\hline AH-1 & Peanuts \\
\hline Rh165 & Sugar beet \\
\hline MWR5-2 & Sugar beet \\
\hline Rh184/S-1 & Sugar beet \\
\hline KF 722-20 & $\mathrm{Nd}^{\mathrm{b}}$ \\
\hline B-81 & Soil \\
\hline SH-1 & Soil \\
\hline R189 & $\mathrm{Nd}^{\mathrm{b}}$ \\
\hline AG95-12 & $\mathrm{Nd}^{\mathrm{b}}$ \\
\hline FK1-1-41 & $\mathrm{Nd}^{\mathrm{b}}$ \\
\hline AO1-7 & Soil \\
\hline NKN 2-1 & Soil \\
\hline YK 2-3 & $\mathrm{Nd}^{\mathrm{b}}$ \\
\hline YK 3-3 & $\mathrm{Nd}^{\mathrm{b}}$ \\
\hline OT 2-1 & Soil \\
\hline 1529 & Soil \\
\hline A 21 & Wheat ${ }^{\mathrm{e}}$ \\
\hline A 125 & Wheat ${ }^{\mathrm{e}}$ \\
\hline SA124 & Barley ${ }^{\mathrm{e}}$ \\
\hline $\mathrm{C} 1$ & Barley ${ }^{f}$ \\
\hline SA1512 & $\mathrm{Oat}^{\mathrm{e}}$ \\
\hline AH-1 & Peanuts \\
\hline YS-6-4-2A & $\mathrm{Nd}^{\mathrm{b}}$ \\
\hline C538 & Potato \\
\hline C460 & Rice \\
\hline C484 & Rice \\
\hline C-314 & Rice \\
\hline C-315 & Rice \\
\hline C-455 & Rice \\
\hline C-350 & Rice \\
\hline Ka-1-1 & Soil \\
\hline TG-SDS-1 & Zoysia grass \\
\hline WP 4 & Zoysia grass \\
\hline $\mathrm{W}-12$ & Zoysia grass \\
\hline BrG-Wp-2 & Zoysia grass \\
\hline WG-IB & Zoysia grass \\
\hline
\end{tabular}




\begin{tabular}{|c|c|c|}
\hline \multirow[t]{5}{*}{ AG-DII } & OK-EF-1 & Rice \\
\hline & WK-EF-1 & Rice \\
\hline & KT-1-1 & Rice \\
\hline & YG-EF-1 & Rice \\
\hline & YC-EF-1 & Rice \\
\hline \multirow[t]{3}{*}{ AG-E } & OC-1 & Woodsorrel \\
\hline & Rh-155 & Soybean \\
\hline & LU-1 & Flax \\
\hline \multirow[t]{2}{*}{ AG-F } & SIR-1 & Sweet potato \\
\hline & A-1-16 & $\mathrm{Nd}^{\mathrm{b}}$ \\
\hline \multirow[t]{4}{*}{ AG-G } & Su-1 & Chickweed \\
\hline & AH-9 & Peanuts \\
\hline & C393 & $\mathrm{Nd}^{\mathrm{b}}$ \\
\hline & $\mathrm{N} 14$ & $\mathrm{Nd}^{\mathrm{b}}$ \\
\hline AG-I & AV-2 & Sage brush \\
\hline AG-K & SH-10 & Soil \\
\hline AG-L & FKO-2-26 & Soil \\
\hline AG-O & FKO-6-2 & Soil \\
\hline AG-P & C-578 & Tea \\
\hline AG-R & $\mathrm{BN}-37$ & Cucumber \\
\hline AG-S & S5 & Soil \\
\hline AG-T & MWR-26 & Rose flower \\
\hline \multirow[t]{6}{*}{ AG-U } & HOK-07-1 & Miniature rose \\
\hline & 99-RM-1 & Miniature rose \\
\hline & 50 it- 800 & Miniature rose \\
\hline & 4Oit- 800 & Miniature rose \\
\hline & 1FUK600 & Miniature rose \\
\hline & 2NIG2-600 & Miniature rose \\
\hline \multicolumn{3}{|l|}{ R. circinata } \\
\hline \multirow[t]{6}{*}{ var. circirnata } & HHC-13-6 & Bentgrass \\
\hline & HTB-A-I & Bentgrass \\
\hline & MAR-BG & Bentgrass \\
\hline & KT-5S-1 & Bentgrass \\
\hline & AMI-BG & Bentgrass \\
\hline & KOUCH-BG & Bentgrass \\
\hline \multirow[t]{6}{*}{ var. agrostis } & HMA-BG & Bentgrass \\
\hline & HIG-BG-A & Bentgrass \\
\hline & NANZ-BG-A & Bentgrass \\
\hline & INAS-BG & Bentgrass \\
\hline & NUK-BG & Bentgrass \\
\hline & HIG-BG-B & Bentgrass \\
\hline \multirow[t]{4}{*}{ var. oryzae } & GH-700 & Zoysia grass \\
\hline & $00-103 \mathrm{~B}$ & Zoysia grass \\
\hline & Mm 9 & Zoysia grass \\
\hline & $\mathrm{Mm}$ 4-3 & Zoysia grass \\
\hline \multirow[t]{4}{*}{ var. zeae } & C504 & Soil \\
\hline & M-003 & Soil \\
\hline & As7s11A & $\mathrm{Nd}^{\mathrm{b}}$ \\
\hline & $11 \mathrm{sh}$ & $\mathrm{Nd}^{\mathrm{b}}$ \\
\hline
\end{tabular}

${ }^{\mathrm{a}}$ Philippines, ${ }^{\mathrm{b}}$ No data, ${ }^{\mathrm{c}}$ Netherlands, ${ }^{\mathrm{d}}$ Spain, ${ }^{\mathrm{e}}$ Australia, ${ }^{\mathrm{f}}$ USA,

${ }^{g}$ Binucleate Rhizoctonia spp. mycoparasite interactions $\mathbf{s}^{1,2,4,9}$. The detection of lectins on hyphal surfaces of some Rhizoctonia spp. also raises the question of whether their presence is related to the recognition process in hyphal anastomosis.

Hyphal anastomosis is spontaneous and seems to be genetically controlled ${ }^{5}$. Perfect fusions are observed only among hyphae originating from a common isolate or plug, while fusion between related isolates results in plasmolysis of fused cells. On the other hand, hyphae from unrelated isolates can only achieve contact fusion, which is not considered anastomosis ${ }^{21}$. Studies have shown that some isolates self anastomose while others do not ${ }^{8,14,26,27)}$. In this study, the presence of lectins in all the known members of the genus Rhizoctonia was investigated and the type of lectins in each species was partially characterized. Also, the distribution of lectins in self-anastomosing isolates (SAIs) and non-self anastomosing isolates (NSAIs) was analyzed and its relationship with the anastomosis phenomenon is discussed.

\section{Materials and Methods}

Isolates used in this study

A total of 144 isolates from Rhizoctonia solani, $R$. circinata and binucleate Rhizoctonia spp. was sampled. Of the sampled isolates, 81 were from $R$. solani, 20 from $R$. circinata, and 43 were from binucleate Rhizoctonia spp. (Table 1).

\section{Extraction of crude lectins}

Mycelia were grown for 16 days at $25^{\circ} \mathrm{C}$ on potato dextrose broth in static cultures. Agar discs $(5 \mathrm{~mm}$, diameter) covered with mycelia were cut from the margins of 5-day old cultures grown on potato dextrose agar (PDA) at $25^{\circ} \mathrm{C}$ and used as inocula. Mycelia were harvested then homogenized using a mortar and pestle in phosphate-buffered saline (PBS-pH 7.4; $8 \mathrm{~g} \mathrm{Nacl}, 2.9 \mathrm{~g} \mathrm{Na}_{2} \mathrm{HPO}_{4} .12 \mathrm{H}_{2} \mathrm{O}, 0.2 \mathrm{~g} \mathrm{KCl}$, $0.2 \mathrm{~g} \mathrm{KH}_{2} \mathrm{PO}_{4}$ in 1 liter of Milli-Q water). Crude lectins (CL) were then extracted overnight in $\mathrm{PBS}$ at $4^{\circ} \mathrm{C}$, and centrifuged at $8000 \mathrm{rpm}, 4^{\circ} \mathrm{C}$ for $15 \mathrm{~min}$ (Tomy-RS 206, Tomy Digital Biological Co., Tokyo, Japan). The supernatants were collected as $\mathrm{CL}$ that were then used for hemagglutination and inhibition assays or stored at $-80^{\circ} \mathrm{C}$ prior to use.

\section{Lectin detection}

Human blood was collected in 3\% sodium citrate. The erythrocytes were washed three times in PBS and suspended at a $3 \%$ concentration in the buffer. A $10 \%$ suspension of erythrocytes in PBS $(10 \mathrm{ml})$ was treated with $7 \mathrm{mg}$ of pro- 
nase (CALBIOCHEM, La Jolla, Canada) for $30 \mathrm{~min}$ at $47^{\circ} \mathrm{C}$. The erythrocytes were then washed three times in PBS and suspended at a concentration of $3 \%$ in the buffer. Agglutination of 3\% erythrocytes and inhibition of the agglutination by sugars and glycoproteins were conducted in 96-well microtiter U-plates (Nalge Nunc International, New York, NY, USA). The titer was defined as a reciprocal of the end-point dilution causing hemagglutination ${ }^{10)}$.

Lectin activity was detected using both treated and untreated blood. The intensity of activity was scored based on hemagglutination patterns that were monitored visually. Agglutination at titers $2^{1}-2^{4}, 2^{5}-2^{8}$, and $2^{9}-2^{11}$ of CL was considered to reflect low (+), moderate (++) and high (+++) lectin activity, respectively (Fig 1). Lack of agglutination (-) indicated that the samples had no lectin activity. For comparison, untreated erythrocyte suspensions were also used.

\section{Carbohydrate inhibition assays}

Two-fold serial dilutions of $10 \mu \mathrm{l}$ of test monosaccharides $(400 \mathrm{mM})$ or glycoprotein $\left(1 \mathrm{mg} \mathrm{ml}^{-1}\right)$ were made in $10 \mu \mathrm{l}$ of PBS across the U-plates. The dilutions were then incubated with $10 \mu \mathrm{l}$ of titer $2^{4} \mathrm{CL}$ at room temperature for 1 hour. The setups were then overlaid with $20 \mu$ of $3 \%$ human erythrocytes, incubated for 30 minutes and then observed. Inhibition was expressed as the minimum

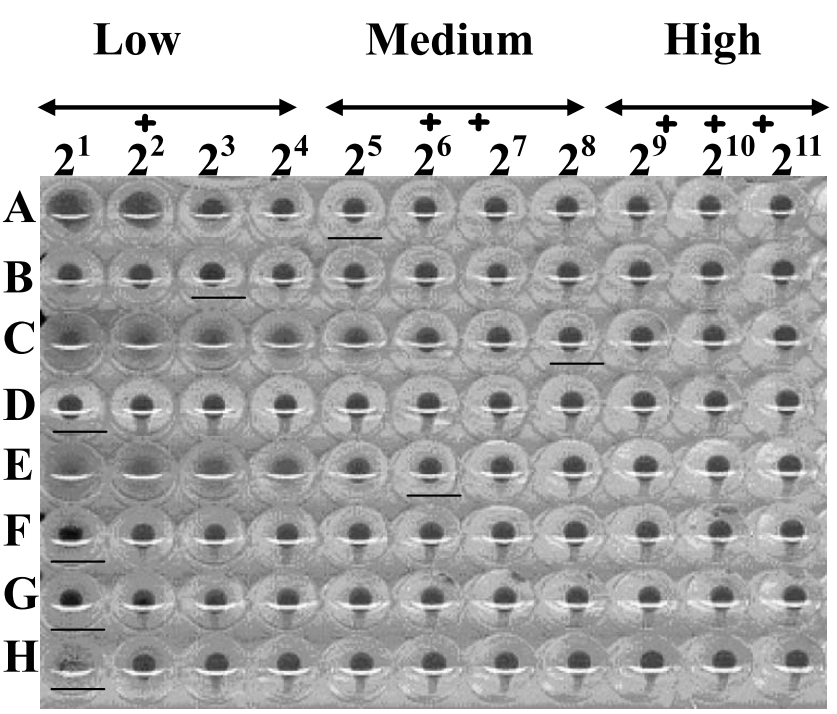

Fig. 1. Lectin detection range using pronase-treated erythrocytes. A$\mathrm{H}$ corresponds to crude lectins (CL) from different isolates tested and line $2^{1}-2^{11}$ to the CL dilution levels (titers). The underbars represent lectin activity levels for each test CL. Agglutination levels at titer $2^{1}-2^{4}, 2^{5}-2^{8}$ and $2^{9}-2^{11}$ were scored as low (+), moderate $(++)$ and as high (+++) lectin intensity, respectively. concentration of each monosaccharide or glycoprotein that was required to inhibit hemagglutination at a titer of $2^{4} \mathrm{CL}$. Lack of agglutination was therefore considered inhibition at that monosaccharide or glycoprotein concentration. Inhibition at titers $2^{1}-2^{4}, 2^{5}-2^{8}$ and $2^{9}-2^{11}$ was considered to reflect respectively, low (+), moderate (++), and high (+++) affinity by the test CL for the carbohydrate tested as indicated in Fig. 2. The tests were repeated at least three times.

\section{Self-anastomosis tests}

Plugs ( $5 \mathrm{~mm}$ diameter) from the margins of 3 to 5 day old PDA cultures were paired opposing each other $(2 \mathrm{~cm})$ on glass slides coated with a thin layer of $2 \%$ water agar (WA). The slides were then incubated under high humidity at room temperature for 2-3 days until hyphal tips made contact. Observations were made under the microscope $(\times 200)$ after staining with $0.1 \%$ cotton blue in lactophenol. The ability of each isolate to self-anastomose or not was determined by observing the hyphal contact points that achieved fusion. Fusion frequencies $(\mathrm{FF})$ were then calculated using the formula, $(\mathrm{FF}=\mathrm{A}(100) / \mathrm{B})$, where $\mathrm{A}$ is the sum of fused contact points and $\mathrm{B}$ the sum of contact points in 15 microscopic

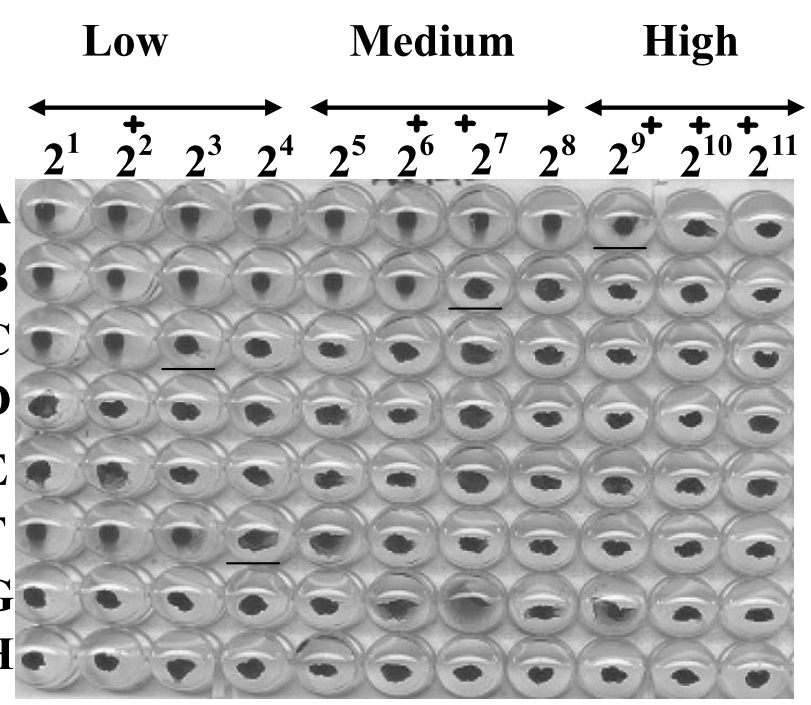

Fig. 2. Affinity range for carbohydrates in the inhibition assays. A 96-well micro-titer U-plate showing the results of carbohydrate inhibition assays using pronase-treated human erythrocytes. A-H corresponds to carbohydrates (GalNAc, galactose, D-fucose, glucose, manose, mucin, asialo-fetiun and fetuin, respectively) against AG 1-IC crude lectins of titer $2^{4}$. Line $2^{1}-2^{11}$ indicate the carbohydrate dilution levels (titers). Hemagglutination between $\mathrm{CL}$ and human erythrocytes was inhibited at titers $2^{9}, 2^{7}, 2^{3}$ and $2^{4}$ (indicated by the underbars) by GalNAc, galactose, D-fucose and mucin, respectively. Inhibition at titers $2^{1}-2^{4}, 2^{5}-2^{8}$ and $2^{9}-$ $2^{11}$ was scored as low (+), moderate (++) and high (+++) affinity, respectively. 
Table 2. Composition and character of isolates used in this study

\begin{tabular}{|c|c|c|c|c|c|c|}
\hline \multirow{2}{*}{ Species } & \multirow{2}{*}{ Number of samples } & \multicolumn{2}{|c|}{ Frequency of occurrence (\%) } & \multicolumn{3}{|c|}{ Lectin occurrence in (\%) } \\
\hline & & SAIs $^{\mathrm{a}}$ & NSAIs ${ }^{b}$ & All samples & SAIs & NSAIs \\
\hline R. solani & 81 & 88 & 12 & 83 & 86 & 60 \\
\hline R. circinata & 20 & 100 & 0 & 0 & 0 & - \\
\hline BNR spp. ${ }^{\mathrm{c}}$ & 43 & 82 & 18 & 7 & 9 & 0 \\
\hline Rhizoctonia species. & 144 & 88 & 12 & 49 & 62 & 35 \\
\hline
\end{tabular}

${ }^{\text {a }}$ Self-anastomosing isolates.

${ }^{\mathrm{b}}$ Non-self-anastomosing isolates.

${ }^{\mathrm{c}}$ Binucleate Rhizoctonia spp.

fields. Fusion frequencies less than $30 \%$ were considered low $(+)$, those between 30 and $50 \%$, moderate $(++)$, and those more than $50 \%$, high $(+++)^{21)}$.

\section{Results and Discussion}

\section{Self-anastomosis phenomenon}

The ability to self-anastomose in isolates of $R$. solani varied from an inability to anastomose to high fusion frequencies across the AGs (data not shown). Out of the 81 isolates sampled from $R$. solani, $88 \%$ were SAIs (Table 2). The occurrence of NSAIs was $12 \%$ in $R$. solani. NSAIs were predominantly (50\%) from AG 2. Similarly, AG 5, AG 6 and AG 8 had some NSAIs. On the other hand, all the 20 isolates sampled from $R$. circinata were SAIs (Table 2). Fusion frequencies in binucleate Rhizoctonia spp. were low for most isolates. However, isolates of AG-DI had high FF values compared to other AGs in this species (data not shown). The occurrence of NSAIs in this species was $18 \%$ (Table 2).

\section{Lectin activity}

Lectin activity in members of $R$. solani ranged from none in isolates of AG 2-2IIIB to high intensity in those of AG 1IA, AG 2-2IV and AG 2-BI (Table 3). These lectins, however, were closely related in their preference for human blood type A over type B and O. R. solani agglutinins (RSA) had affinity for GalNAc $(0.1 \mathrm{mM}-100 \mathrm{mM})$, galactose $(0.8 \mathrm{mM}-100 \mathrm{mM})$ and D-fucose $(13 \mathrm{mM}-100 \mathrm{mM})$ in that order of preference across the AGs. Also, lectins from all sampled AGs had affinity for a glycoprotein, mucin, at concentrations ranging from $0.8 \mu \mathrm{g} \mathrm{ml}^{-1}$ to $250 \mu \mathrm{g} \mathrm{ml}^{-1}$ across the AGs. Affinity levels for carbohydrates generally varied across the AGs in $R$. solani (Tables 3 and 4). Interestingly, the 20 isolates sampled from $R$. circinata had no lectin activity at all (Table 2).

Only 7\% of the isolates from binucleate Rhizoctonia spp. had lectin activity. These isolates belonged to AG-DII. The intensity, however, was low in this genus (Table 3). The occurrence of lectins in SAIs of $R$. solani was $86 \%$ while that in NSAIs was $60 \%$ (Table 2). However, in binucleate Rhizoctonia spp., lectin was detected in $9 \%$ of the SAIs. None of the NSAIs in this genus had lectins (Table 2). Out of all Rhizoctonia isolates sampled, $62 \%$ of the anastomosing and $35 \%$ of the non-anastomosing isolates had lectins detected at varying concentrations (Table 2).

Lectin activity in Rhizoctonia fungi varied sharply across the species with $R$. solani having intense activity and a few binucleate Rhizoctonia spp. having weak activity. Our results concur with those of Kellens et al. (1991) who reported no lectins in members of $R$. circinata $^{13)}$. Agglutination profiles in RSA revealed a close relationship among anastomosis groups of $R$. solani. There was a general preference for blood type A over B and O. Certain isolates within and among AGs, however, exhibited individual preferences with some isolates from AG 1-IB and AG 7 having preference for blood type A only, while AG 2-3 preferred blood type O over A and B (Table 3). Agglutination profiles, however, did not conclusively divide the $R$. solani isolates into their distinct AGs but rather expressed some relatedness among them. This relatedness is also expressed by the common affinity for GalNAc and mucin.

The distinct absence of lectins in members of AG 2-2IIIB and some members of AG 6 , however, marked a major variation in lectin activity in this species. AG-DII isolates from binucleate Rhizoctonia spp. had lectins with agglutination profiles (A over B and O) similar to RSA in blood type preference (Table 3). These lectins, however, had affinity for only glycoproteins, fetuin and mucin. From the agglutination profiles, AG-DII lectins show some relationship to RSA but are distinctly different in their specificity for carbohydrates. Generally Rhizoctonia lectins had preference for human blood type $\mathrm{A}$ over $\mathrm{B}$ and $\mathrm{O}$ and had affinity for mucin. None of the Rhizoctonia lectins tested had affinity for glucosamine, $N$-acety-D-glucosamine, nor 
Table 3. Lectin variation in Rhizoctonia species

\begin{tabular}{|c|c|c|c|c|c|c|}
\hline \multirow{2}{*}{$\mathrm{AG}$} & \multirow{2}{*}{$\begin{array}{l}\text { No. of isolates } \\
\text { sampled }\end{array}$} & \multicolumn{2}{|c|}{ Lectin activity } & \multirow{2}{*}{$\begin{array}{l}\text { Blood type } \\
\text { preference }\end{array}$} & \multicolumn{2}{|c|}{ Carbohydrate affinity } \\
\hline & & $\begin{array}{c}\text { Frequency } \\
(\%)\end{array}$ & Intensity & & Monosaccharides & Glycoprotein \\
\hline \multicolumn{7}{|l|}{ R. solani } \\
\hline AG I-IA & 5 & 100 & +++ & $\mathrm{A}>\mathrm{O}>\mathrm{B}$ & GalNAc $>$ Gal & Mucin \\
\hline AG 1-IB & 3 & 100 & ++ & A & GalNAc,Gal $>$ D-fuc & Mucin $>\mathrm{Fet}^{\mathrm{a}}$ \\
\hline AG 1-IC & 5 & 100 & + & $\mathrm{A}>\mathrm{B}>\mathrm{O}$ & GalNAc $>$ Gal & Mucin \\
\hline AG 1-ID & 3 & 100 & ++ & $\mathrm{A}>\mathrm{O}>\mathrm{B}$ & GalNAc & Mucin \\
\hline AG 2-1 & 3 & 100 & ++ & $\mathrm{A}, \mathrm{B}>\mathrm{O}$ & - & Mucin \\
\hline AG 2-2IIIB & 5 & 0 & - & - & - & - \\
\hline AG 2-2IV & 7 & 100 & +++ & $\mathrm{A}>\mathrm{O}>\mathrm{B}$ & GalNAc & Mucin \\
\hline AG 2-2LP & 6 & 100 & ++ & $\mathrm{A}, \mathrm{O}>\mathrm{B}$ & - & Mucin \\
\hline AG 2-t & 7 & 100 & ++ & $\mathrm{A}, \mathrm{B}, \mathrm{O}$ & - & Mucin \\
\hline AG 2-3 & 6 & 100 & ++ & $\mathrm{O}>\mathrm{A}>\mathrm{B}$ & GalNAc & Mucin \\
\hline AG 2-BI & 2 & 100 & +++ & $\mathrm{A}>\mathrm{B}>\mathrm{O}$ & GalNAc, Gal & Mucin \\
\hline AG 3 & 7 & 86 & ++ & $\mathrm{A}>\mathrm{O}>\mathrm{B}$ & - & Mucin \\
\hline AG 4 & 4 & 75 & ++ & $\mathrm{A}>\mathrm{B}>\mathrm{O}$ & GalNAc $>$ Gal,D-Fuc & Mucin \\
\hline AG 5 & 6 & 67 & + & $\mathrm{A}>\mathrm{B}>\mathrm{O}$ & - & Mucin \\
\hline AG 6 & 6 & 17 & \pm & $\mathrm{A}>\mathrm{O}>\mathrm{B}$ & - & Mucin \\
\hline AG 7 & 1 & 100 & + & A & GalNAc $>$ Gal & Mucin \\
\hline AG 8 & 5 & 100 & ++ & $\mathrm{A}>\mathrm{B}>\mathrm{O}$ & GalNAc & Mucin $>$ Fet \\
\hline \multicolumn{7}{|l|}{ R. circinatab $^{\mathrm{b}}$} \\
\hline var. circinata & 6 & 0 & - & - & - & - \\
\hline var. agrostis & 6 & 0 & - & - & - & - \\
\hline var. oryzae & 4 & 0 & - & - & - & - \\
\hline var. zeae & 4 & 0 & - & - & - & - \\
\hline \multicolumn{7}{|c|}{ Binucleate Rhizoctonia spp } \\
\hline AG-A & 3 & 0 & - & - & - & - \\
\hline AG-Ba & 4 & 0 & $\mathrm{~T}^{\mathrm{c}}$ & $\mathrm{A}$ & - & - \\
\hline $\mathrm{AG}-\mathrm{Bb}$ & 2 & 0 & - & - & - & - \\
\hline AG-C & 1 & 0 & - & - & - & - \\
\hline AG-DI & 5 & 0 & - & - & - & - \\
\hline AG-DII & 5 & 60 & + & $\mathrm{A}, \mathrm{B}>\mathrm{O}$ & - & Fet $>$ Mucin \\
\hline AG-E & 3 & 0 & - & - & - & - \\
\hline AG-F & 2 & 0 & - & - & - & - \\
\hline AG-G & 4 & 0 & - & - & - & - \\
\hline AG-I & 1 & 0 & - & - & - & - \\
\hline AG-K & 1 & 0 & - & - & - & - \\
\hline AG-L & 1 & 0 & - & - & - & - \\
\hline AG-O & 1 & 0 & - & - & - & - \\
\hline AG-P & 1 & 0 & $\mathrm{~T}$ & A & - & - \\
\hline AG-R & 1 & 0 & - & - & - & - \\
\hline AG-S & 1 & 0 & - & - & - & - \\
\hline AG-T & 1 & 0 & - & - & - & - \\
\hline AG-U & 6 & 0 & - & - & - & - \\
\hline
\end{tabular}

${ }^{\mathrm{a}}$ Fetuin.

${ }^{\mathrm{b}}$ All four varieties of $R$. circinata tested were SAI without lectins.

c Traces. 
Table 4. Carbohydrates specificity of $\mathrm{RSA}^{\mathrm{a}}$ and $\mathrm{BNR}^{\mathrm{b}}$ lectins

\begin{tabular}{|c|c|c|c|c|c|c|c|c|c|c|}
\hline \multirow{2}{*}{$\mathrm{AG}$} & \multicolumn{7}{|c|}{ Monosaccharides (mM) } & \multicolumn{3}{|c|}{ Glycoprotein $\left(\mu \mathrm{g} \mathrm{ml}^{-1}\right)$} \\
\hline & GalNAc & GlcNAc & Gal & L-Fuc & D-Fuc & Man & Glc & A/fetuin ${ }^{c}$ & Fetuin & Mucin \\
\hline AG I-IA & 1.6 & - & 25.0 & - & - & 一 & - & - & - & 7.5 \\
\hline AG 1-IB & 0.4 & - & 0.8 & - & 13.0 & - & - & 1.5 & 0.2 & 1.5 \\
\hline AG 1-IC & 0.4 & - & 1.6 & - & 25.0 & - & - & - & - & 31.0 \\
\hline AG 1-ID & 25.0 & - & 100.0 & - & - & - & - & - & - & 16.0 \\
\hline AG 2-1 & 0.8 & - & 6.3 & - & 50.0 & - & - & - & - & 31.0 \\
\hline AG 2-2IIIB & $* \mathrm{~d}$ & $*$ & $*$ & $*$ & $*$ & * & $*$ & $*$ & $*$ & $*$ \\
\hline AG 2-2IV & $>100.0$ & - & - & - & - & - & - & - & - & 0.8 \\
\hline AG 2-2LP & $>100.0$ & - & - & - & - & - & - & - & - & 1.5 \\
\hline AG 2-t & 0.4 & - & 0.8 & - & 13.0 & - & 100.0 & - & - & 31.0 \\
\hline AG 2-3 & $>100$ & - & - & - & - & - & - & - & - & 16.0 \\
\hline AG 2-BI & 1.6 & - & 13.0 & - & 100.0 & - & - & - & - & 250.0 \\
\hline AG 3 & $>100$ & - & - & - & - & - & - & - & - & 3.6 \\
\hline AG 4 & 0.4 & - & 6.3 & - & 25.0 & - & - & - & - & 31.0 \\
\hline AG 5 & $>100.0$ & - & - & - & - & - & - & - & - & 16.0 \\
\hline AG 6 & $>100.0$ & - & - & - & - & - & - & 125.0 & - & 1.5 \\
\hline AG 7 & 0.1 & - & 1.6 & - & - & - & - & - & - & 1.5 \\
\hline AG 8 & 50.0 & - & - & - & - & - & - & 125.0 & 250.0 & 1.5 \\
\hline AG-DII ${ }^{b}$ & - & - & - & - & - & - & - & - & 0.8 & 7.5 \\
\hline
\end{tabular}

${ }^{a}$ Rhizoctonia solani agglutinins from AG 1 to AG 8.

${ }^{\mathrm{b}}$ Binucleate Rhizoctonia (AG-DII) lectins.

${ }^{c}$ Asialo fetuin.

${ }^{\mathrm{d}}$ No data due to lack of lectins in members of the AG. The values in the table represent the minimum concentrations of monosaccharides (mM) and glycoprotein $\left(\mu \mathrm{g} \mathrm{ml}^{-1}\right)$ that inhibited hemagglutination to RSA and BNR lectins. Low values indicate high affinity of the test CL for the respective test carbohydrate. The titer of RSA and BNR lectins used in this test was $2^{4}$.

\section{L-fucose (Table 4).}

The involvement of lectins in the fungus-mycoparasite and cell-cell recognition process has recently been elucidated ${ }^{2,499}$. Elad et al. (1983) suggested that lectins on the surfaces of $R$. solani act as an elicitor, while the galactose molecules on Trichoderma harzianum hyphae respond (receptor) to stimuli in a fungus-mycoparasite interaction. Similarly, Inbar and Chet (1992) demonstrated using nylon fiber biomimics, that lectins are directly involved in the recognition process of the mycoparasitic fungus, T. harzianum to Sclerotium rolfsii ${ }^{9}$. The presence of lectins on hyphal surfaces of Rhizoctonia fungi suggests that they may also be involved in the recognition process in hyphal anastomosis. Ideally, SAIs should have both elicitor and receptor sites along the hyphae as hypothesized by Kuninaga $(1980)^{14)}$ and Yokoyama et al. $(1985)^{26,27)}$. A lack of either one of these will, therefore, result in the inability of that hyphae to self-anastomose.

Most patterns of anastomosis are mediated from the tips of the hyphae although there are cases of side-by-side con- tacts that also result in fusion. In our experiments, both SAIs and NSAIs clearly showed the presence of lectins on hyphal surfaces when challenged with pronase- treated human erythrocytes (Figs. $3 a$ and $3 b$ ). Binding was distinctly noted on the older cells of the hyphae rather than the growing tips. In contrast, isolates from $R$. circinata and some from binucleate Rhizoctonia spp. and R. solani that anastomosed at different frequencies did not have any lectins at all. Furthermore, tests using various monosaccharides as lectin inhibitors in membrane bioassays did not reveal any significant change in the fusion frequencies of SAIs nor NSAIs (data not shown).

Media containing L-asparigine have been reported to strongly affect the lectin content in $R$. solani cultures ${ }^{12}$. The introduction of L-asparagine monohydrate $\left(4 \mathrm{~g} \mathrm{~L}^{-1}\right)$ in $2 \%$ WA bioassay setups had a significant increase on the FF of SAIs but had no effect on that of NSAIs. This change was possibly nutritional because extensive hyphal branching was noted for both NSAIs and SAIs. Consequently, more hyphal contact points and subsequently more fusions were 

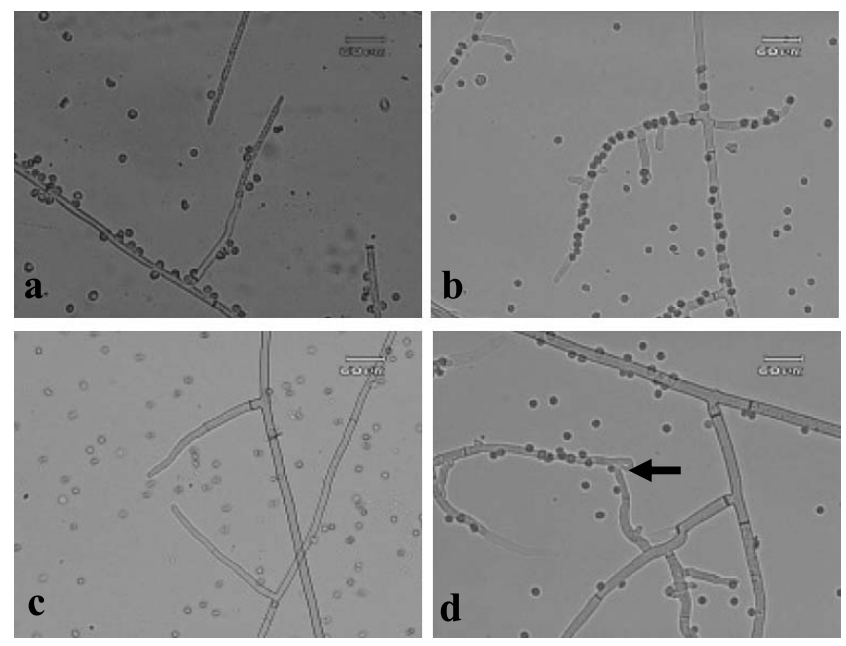

Fig. 3. Lectin deposition sites on hyphae of a SAI and NSAI from Rhizoctonia solani AG 2-2IV. Continued from LIST OF FIGURES. a: Hyphae of isolate H16 (NSAI) challenged with pronase-treated human erythrocytes. Erythrocyte attachment points indicate lectin deposition sites. b: Hyphae of isolate SA-1 (SAI) showing more lectin sites on older hyphal cells compared to the growing tips. A similar phenomenon is observed in Fig. 3a. c, d: show SA-1 hyphae at the recognition stage (c) and after hyphae have fused (d). The deposition of lectin on the hyphal surfaces is not concentrated at the fusion sites during anastomosis.

realized for SAIs but no fusion occurred in NSAIs (data not shown).

The Rhizoctonia lectins isolated to date have been characterized as dimers or tetramers with rare cases of monomers, suggesting that they are more active as aggregates and do play a major biological role in the species ${ }^{1,3,11,12,13,24)}$. Although lectin on the hyphal surfaces of Rhizoctonia fungi have previously been demonstrated to be a fungal-fungal recognition component, preliminarily, our data did not correlate lectin with the anastomosis recognition process. However, the close similarity in carbohydrate specificity and preferential affinity for human blood type A in Rhizoctonia lectins demonstrates a close relationship among lectins from this species. Individual specific characters, however, are occasionally exhibited. To the best of our knowledge this is the first report characterizing lectins from binucleate Rhizoctonia spp.

\section{Acknowledgements}

The authors are grateful to M. Julian, S. Neate, D.E. Carling, J.H.M. Schneider and C. Pascual for providing isolates of $R$. solani. Members of the Plant Pathology Laboratory, Gifu University, are acknowledged for their invaluable support through blood donations, while O.-A. Siaw is acknowledged for his comments and critical reading of the manuscript. This work was supported by grants from the Ministry of Education, Culture, Sports, Science and Technology, Japan.

\section{References}

1) Barak, R. and I. Chet. 1990. Lectin of Sclerotium rolfsii: its purification and possible function in fungal- fungal interaction. $\mathrm{J}$. Appl. Bacteriol. 69: 101-112.

2) Barak, R., Y. Elad, D. Mirelman and I. Chet. 1985. Lectins; a possible basis for specific recognition in Trichoderma-Sclerotium rolfsii interaction. Phytopathology 75: 458-462.

3) Barondes, S.H. 1981. Lectins: their multiple endogenous cellular functions. Annu. Rev. Biochem. 50: 207-231.

4) Elad, Y., R. Barak and I. Chet. 1983. Possible role of lectins in Mycoparasitism. J. Bacteriol. 154: 1431-1435.

5) Flentje, N.T. and H.M. Stretton. 1964. Mechanism of variation in Thanatephorus cucumeris and T. practicolus. Aust. J. Biol. Sci. 17: 686-704.

6) Goldstein, I.J., R.C. Hughes, M. Monsigny, T. Osawa and N. Sharon. 1980. What should be called a lectin? Nature 285: 66.

7) Hietala, A.M., R. Sen, and A. Lilja. 1994. Anamorphic and teleomorphic characteristics of a uninucleate Rhizoctonia sp. isolated from roots of nursery grown conifer seedlings. Mycol. Res. 98: 1044-1050.

8) Hyakumachi, M. and T. Ui. 1987. Non-self-anastomosing isolates of Rhizoctonia solani obtained from fields of sugar beet monoculture. Trans. Br. Mycol. Soc. 89: 155-159.

9) Inbar, J. and I. Chet. 1992. Biomimics of fungal cell-cell recognition by use of lectin-coated nylon fibers. J. Bacteriol. 174: 1055-1059.

10) Kawagishi, K., M. Yamawaki, S. Isobe, T. Usui, A. Kimura and S. Chiba. 1994. Two lectins from the marine sponge Halichondria okadai; an $\mathrm{N}$-acetyl-sugar specific (HOL-I) and an $\mathrm{N}$-acetyllactosamine specific lectin (HOL-II). J. Biol. Chem. 269: 1375-1379.

11) Kellens, J.T.C., A.K. Allen and W.J. Peumans. 1989. Isolation and characterization of lectins from Rhizoctonia crocorum and Athelia rolfsii. J. Gen. Microbiol. 135: 3127-3132.

12) Kellens, J.T.C. and W.J. Peumans. 1990. Developmental accumulation of lectin in Rhizoctonia solani: a potential role as a storage protein. J. Gen. Microbiol. 136: 2489-2495.

13) Kellens, J.T.C. and W.J. Peumans. 1991. Biochemical and serological comparison of lectins from different anastomosis groups of Rhizoctonia solani. Mycol. Res. 95: 1235-1241.

14) Kuninaga, S. 1980. Hyphal anastomosis behavior of single basidiospore isolates in Thanatephorous cucumeris (Frank) Donk. Higashi Nippon Gakuen Journal of Liberal Arts and Science 6: 95-106.

15) Kuninaga, S. 2002. Current situation of the taxonomy of the genus Rhizoctonia and the $R$. solani species complex. Jpn. J. Phytopathol. 68: 3-20 (in Japanese).

16) Neate, S.M. and J.H. Warcup. 1985. Anastomosis grouping of some isolates of Thanatephorus cucumeris from agricultural soils in South Australia. Trans. Brit. Mycol. Soc. 85: 615-620.

17) Ogoshi, A. 1976. Studies on the grouping of Rhizoctonia solani 
Kuehn with hyphal anastomosis and on the perfect stages of groups. Bull. Nat. Inst. Agr. Sci. Ser. C. 30: 1-63 (in Japanese).

18) Ogoshi, A., M. Oniki, T. Araki and T. Ui. 1983. Anastomosis groups of binucleate Rhizoctonia in Japan and North America and their perfect states. Trans. Mycol. Soc. Jpn 24: 79-87 (in Japanese).

19) Parmeter, J.R.Jr., R.T. Sherwood and W.D. Platt. 1969. Anastomosis grouping among isolates of Thanatephorus cucumeris. Phytopathology 59: 1270-1278.

20) Priyatmojo, A. 2001. Identification, characterization and differentiation of Rhizoctonia species using conventional, biochemical and molecular techniques. PhD thesis, The United Graduate School of Agricultural Science, Gifu University, Gifu, Japan.

21) Sneh, B., L. Burpee and A. Ogoshi. 1991. Identification of Rhizoctonia species. APS press, St. Pauls, Minnesota, USA.

22) Toda, T. 2003. Identification and detection of Rhizoctonia species using molecular techniques. PhD thesis, The United Graduate School of Agricultural Science, Gifu University, Gifu, Japan.
23) Toda, T., M. Hyakumachi, H. Suga, K. Kageyama, A. Tanaka and T. Tani. 1999. Differentiation of Rhizoctonia AG-D isolates from turf-grass into sub groups I and II based on rDNA and RAPD analyses. Eur. J. Plant Pathol. 105: 835-846.

24) Vranken, M., J.M. Van Damme, A.K. Allen and W.J. Peumans. 1987. Purification and properties of an $N$-acetylgalactosamine specific lectin from the plant pathogenic fungus Rhizoctonia solani. FEBS Lett. 216: 67-72.

25) Wenzler, R.J. 1970. Carbohydrates in cell surfaces. Int. Rev. Cytol. 23: 77-125.

26) Yokoyama, K., M. Hyakumachi and A. Ogoshi. 1985. Studies on hyphal anastomosis of Rhizoctonia solani III. Hyphal anastomosis in non-self-anastomosis isolates. Mem. Fac. Agric., Hokkaido University, 14: 416-421 (in Japanese).

27) Yokoyama, K., A. Ogoshi and T. Ui. 1985. Studies on hyphal anastomosis of Rhizoctonia solani II. The ultrastructural changes of hyphal cell during perfect fusion. Trans. Mycol. Soc. Jpn. 26: 199-207. 